\title{
Magnetic-activated cell sorting improves high- quality spermatozoa in bovine semen
}

\author{
Teresinha Inês de Assumpção ${ }^{1 *}$, Neimar Correa Severo², João Pedro Brandão Zandonaide ${ }^{3}$ and \\ Gustavo Guerino Macedo ${ }^{4}$ \\ ${ }^{1}$ Faculty of Veterinary Medicine and Animal Science, Federal University of Uberlandia, Uberlandia 38400902, Brazil, \\ ${ }^{2}$ RevivaH Technical Consultancy, Uberaba 38017200, Brazil, \\ ${ }^{3}$ Alta Genetics, Uberaba 38055010, Brazil, \\ ${ }^{4}$ Faculty of Veterinary Medicine and Animal Science, Federal University of Mato Grosso do Sul, Campo Grande \\ 79070900, Brazil
}

Received March 22, 2021

Revised April 28, 2021

Accepted June 6, 2021

\section{*Correspondence}

Teresinha Inês de Assumpção

E-mail: teassumpcao@ufu.br

ORCID

https://orcid.org/0000-0001-8323-9348

\begin{abstract}
The objective of this study was to establish a selection process for high quality sperm in bovine semen using sperm separation by magnetic activation (MACS). For this, semen from 21 Nellore bulls was collected using an artificial vagina. To guarantee the presence of pathologies in the ejaculate, animals previously declassified in four consecutive spermiogram were used. Semen was analyzed in five statuses: (1) fresh semen (fresh); (2) density gradient centrifugation (DGC), percoll column; (3) non-apoptotic fraction after separation by MACS (MAC); (4) apoptotic fraction from the separation (MACPOOR); and (5) MAC followed by DGC (MACDGC). Using a computerized analysis system (CASA), motility was measured. The sperm morphology was evaluated by phase contrast, and the supravital test was completed with eosin/nigrosin staining. For DGC, $20 \times 10^{6}$ cells were used in a gradient of $90 \%$ and $45 \%$ percoll. MACS used $10 \times 10^{6}$ cells with $20 \mu \mathrm{L}$ of nanoparticles attached to annexin $\mathrm{V}$, and filtered through the MiniMACS magnetic separation column. Membrane integrity was assessed with SYBR-14/IP and mitochondrial potential with JC-1 by flow cytometry. Processing sperm by MACDGC, was more effective in obtaining samples with high quality sperm, verified by the total of abnormalities in the samples: $35.04 \pm 2.29 \%, 21.50 \pm 1.47 \%$, $17.30 \pm 1.10 \%, 30.68 \pm 1.94 \%$ and $10.50 \pm 1.46 \%$, respectively for fresh, DGC, MAC, MACPOOR, and MACDGC. The subpopulation of non-apoptotic sperm had a high number of live cells (82.65\%), membrane integrity (56.60\%) and mitochondrial potential $(83.98 \%)(p<0.05)$. These findings suggest that this nanotechnological method, that uses nanoparticles, is efficient in the production of high-quality semen samples for assisted reproduction procedures in cattle.
\end{abstract}

Keywords: andrology, bull, ejaculate, fertility, sperm

\section{INTRODUCTION}

Millions of bovine females are inseminated annually around the world, with 80,938,152 females in Brazil insem- inated in 2020 , representing $19.4 \%$ of the national female herd (ASBIA, 2021). Despite this high number of inseminations, the probability of conception is around $50 \%$, due low seminal quality and injuries caused by cryopreserva- 
tion, which both affect fertilization and/or embryonic development (Sá Filho et al., 2009). The increasing adoption of artificial insemination and cryopreservation of semen has increased the need to develop methods to specify the fertility of bulls. Since the beginning of the 20th century the poor quality of sperm cells has been associated with low fertility, and the evaluation of sperm morphology has been used in the reproductive health examination or research of low fertility of animals (Nöthling and Irons, 2008).

Semen quality is very variable, even in a single individual, which has an impactful relationship with fertility, since any factor capable of altering spermatogenesis results in the production of sperm with morphological changes (de Arruda et al., 2015). Sperm quality is one determinant of successful in vivo and in vitro reproduction techniques (Rawe et al., 2009; Odhiambo et al., 2014). In human medicine, the separation of viable sperm in the ejaculate is in great demand for embryo production, since human semen has a high number of morphological abnormalities (Berteli et al., 2017). In cattle, density gradient centrifugation (DGC) is used, which separates mobile sperm from the solution (Missio et al., 2018); however, it does not separate head and membrane pathologies and is not viable for large-scale production due to its low efficiency and high cost.

Phosphatidylserine (FTS) is a phospholipid located on the cytosolic side of the sperm cell membrane, and its externalization is considered a sign of apoptosis, as it causes membrane fluidity, breaks the mitochondrial membrane potential, and activates caspases and fragmentation of DNA (Aziz et al., 2007; Tavalaee et al., 2012). Thus, FTS externalized (apoptosis) is associated with a decrease in seminal parameters, such as motility, morphology, and concentration, and, consequently, leads to reduced fertility (Said et al., 2008; Rawe et al., 2009; Tavalaee et al., 2012). The presence of these apoptosis markers is directly correlated with in vivo and in vitro fertility failures (Tavalaee et al., 2012). Annexin V (ANX) is a protein that specifically binds to FTS and is used to identify cells with altered membranes, beginning at apoptosis (Kurz et al., 2005).

The technique of cell separation by magnetic activation (MACS) is a non-invasive method that uses knowledge of ANX affinity with the FTS membrane. ANX, when coupled to metallic microspheres, binds to sperm with damaged membranes. By submitting this conjugate (nanoparticles + ANX + sperm) to a high-potency magnetic field in a separation column, it adheres to the column, while nonapoptotic cells with intact membranes pass freely through it (Dirican et al., 2008; Rawe et al., 2009; Manuel et al., 2017), thus separating normal sperm from those with abnormalities. MACS increases the number of normal cells, as well as motility and morphology (Curti et al., 2014) with good results in human in vitro fertilization (Manuel et al., 2017), yielding a cell recovery rate in around 73.8 $\pm 12.1 \%$ for human species (Said et al., 2006). In animal species, studies using MACS and measuring the efficiency of sperm cells in vivo and in vitro post-selection are still required.

Thus, the development of a sperm separation technique that does not interfere with sample quality will allow for the production of high-quality semen samples from domestic animals, with a high chance of fertility of the oocyte. This will contribute to the increase in postinsemination reproductive efficiency or the production of embryos in vitro. In view of this, the present study aimed to carry out spermatozoa selection through sperm separation by MACS and/or DGC/percoll in fresh bovine semen, evaluating the quality of cells after the sperm selection process.

\section{MATERIALS AND METHODS}

Semen collections were approved by Ethics Committee on the Use of Animals of the Federal University of Uberlandia, in 22 June 2018, protocol 024/18. This study was carried out in a semen collection and processing center (Alta Genetics, Uberaba, Brazil) with Nellore bulls ( $\mathrm{n}=$ 21), submitted once a week to ejaculate collections using the artificial vagina technique, collecting all the semen produced by the animal. To guarantee the presence of pathologies in the ejaculates, animals declassified in the spermiogram were selected (CBRA, 2013), as they have high numbers of cells with abnormalities (above 30\%). Semen was analyzed after five steps in the collection/ separation process: 1) fresh semen immediately after collection (FRESH); 2) density gradient centrifugation (DGC), percoll column; 3) after separation by MACS (filtered portion was good; MAC); 4) after separation by MACS (portion retained in the column was bad; MACPOOR); and 5) separation by MACS (filtered portion was good), followed 
by DGC/percoll (MACDGC) (Fig. 1). In each sample, the following analyses were performed: total and progressive motility by computerized semen analysis (CASA) in IVOS model equipment (Hamilton Thorne ${ }^{\circledR}$ ) (Valverde and Madrigal-Valverde, 2018), sperm morphology assessed in a wet chamber under phase contrast optical microscopy (CBRA, 2013); and the supravital test with semen smears stained by eosin-nigrosin (Botuvital ${ }^{\circledR}$, Botupharma, Botucatu, SP), to verify the proportion of spermatozoa living and dead (Faezah et al., 2014).

For sperm separation in DGC, a percoll ${ }^{\mathrm{TM}}$ stock solution (Sigma-Aldrich, St Louis, USA) was prepared, composed of $90 \%$ percoll ( $\mathrm{pH} 7.4 ; 280-290 \mathrm{mOsm} / \mathrm{kg} \mathrm{H}_{2} \mathrm{O}$ ), in Eagle's medium modified by Dubelcco concentrate $10 \times$ (Sigma-Aldrich, St Louis, USA), containing 0.3\% BSA (Calbiochem, Darmstadt, Germany), $10 \mathrm{mg} / \mathrm{L}$ antibiotic, and 6 mM HEPES (Sigma-Aldrich, St Louis, USA), with the $\mathrm{pH}$ adjusted to 7.4. The percoll density gradient was prepared by depositing $200 \mu \mathrm{L}$ of TALP-SPERM with $200 \mu \mathrm{L}$ of the $90 \%$ percoll solution in a $1.5 \mathrm{~mL}$ microtube, thus, forming the $45 \%$ percoll layer. Below this, $400 \mu \mathrm{L}$ of $90 \%$ percoll was deposited. Semen containing 20 million sperm was deposited above the column, following the protocol of Missio et al. (2018), with modifications. Microtubes were centrifuged at $900 \times \mathrm{G}$ for $5 \mathrm{~min}$ at room temperature. The sediment containing the sperm was diluted in $150 \mu \mathrm{L}$ HEPES for cell analysis (Machado et al., 2009).

For sperm separation by MACS, protocol adapted from the MACS columns' manufacturer (Miltenyi Biotec, Germany) was used, as described by Rawe et al. (2009). From fresh semen, a solution of $1.5 \mathrm{~mL}$ of HEPES containing 10 million sperm was prepared, followed by centrifugation at $300 \times \mathrm{G}$ for $10 \mathrm{~min}$, to wash the sperm. The pellet formed was resuspended in $150 \mu \mathrm{L}$ HEPES, and $20 \mu \mathrm{L}$ of iron nanoparticles linked to ANX (Miltenyi Biotec, Germany) were added. After incubation for $15 \mathrm{~min}$ at room temperature, filtration was performed on the MiniMACS magnetic separation column (Miltenyi Biotec, Germany). The column was hydrated with $500 \mu \mathrm{L}$ of phosphate buffered saline containing $0.3 \%$ BSA. The filtrate, or nonapoptotic fraction, was collected directly from the column in a $2 \mathrm{~mL}$ tube (MAC). The apoptotic fraction, joined by microspheres in the column (MACPOOR), was obtained by removing the column from the magnet and adding $300 \mu \mathrm{L}$ of HEPES with the help of a plunger. Sperm separation by MACS followed by DGC/percoll was a combination of the two methodologies described above.

Plasma membrane integrity was assessed in flow cytometry $\left(\right.$ Cyflow $\left.^{\circledR}\right)$ using $10 \mu \mathrm{L}$ semen with $2 \mu \mathrm{L}$ propidium iodide (28707-5, St Louis, MO, USA) and $1 \mu \mathrm{L}$ of SYBR-14 (Sperm Viability kit, L-7011, Molecular Probes, Eugene, USA), with a total of 5,000 cells being evaluated. For the analysis of mitochondrial potential, one million sperm were used, diluted in $150 \mu \mathrm{L}$ of HEPES with $6 \mu \mathrm{L}$ of JC-1 (5,5',6,6' -tetrachlor-1,1,3,3' -tetraethylbenzimidazolylcarbocyanine iodide; Molecular Probes, T-3168, Sigma-Aldrich, St Louis, USA). After incubation for $8 \mathrm{~min}$ at room temperature, protected from light, the samples were fixed with $4 \%$ paraformaldehyde $(3 \mu \mathrm{L})$ and evaluated by flow cytometry (Cytoflex ${ }^{\circledR}$ ); Celeghini et al. (2007) with adaptations.

Statistical analysis was performed with the aid of the Statistical Analysis System for Windows SAS ${ }^{\circledast}$ program (SAS University). Continuous variables were assessed for normality of residues by the UNIVARIATE procedure and subjected to the Bartlett test to verify the homogeneity of variances. The data was submitted to the GLIMMIX procedure, followed by the Tukey test. Normal distribution de-

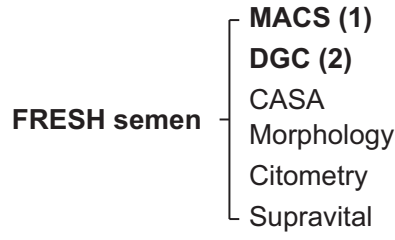

(1) MACS $-\left[\begin{array}{cc}\text { MAC (non apoptotic) } & \longrightarrow \text { Morphology, citometry, CASA, supravital, DGC } \\ \text { MACPOOR (apoptotic) } \longrightarrow \text { Morphology, citometry, CASA, supravital }\end{array}\right.$

(2) DGC $-[$ Morphology, citometry, CASA, supravital
Fig. 1. Experimental design (DGC, density gradient centrifugation; MACS, magnetic cell separation). 
pendent variables (parametric) were expressed as adjusted means and standard error of the mean (mean \pm SEM). A significant difference was considered when $p<0.05$ and trend $p<0.10$.

\section{RESULTS}

Ejaculate volumes ranged from 6 to $10 \mathrm{~mL}$. Concentrations in FRESH semen were $412 \times 10^{6}$ to $2325 \times 10^{6}$ sperm $/ \mathrm{mL}$ (mean of $828 \times 10^{6}$ per $\mathrm{mL}$ ). Treatments influenced total and progressive motilities, observing a decrease in motility with increased manipulation of the semen observing an effect of the increased manipulation in the semen in the decrease of motility (Fig. 2). DGC increased the sperm's progressive motility by about $15 \%$ in relation to FRESH semen. MAC's motility was more than 30\% higher than MACPOOR. Both MACPOOR and MACDGC had the lowest motility values (Fig. 2). Fig. 3 shows the parameters of major, minor, and total abnormalities in both FRESH semen and after the different selection procedures. Larger and total defects, more strongly related to infertility, were present in low quantity after DGC, MAC, and MACDGC. Individually, the DGC and MACS techniques reduced total sperm abnormalities by about 50\%; however, the combination of the two methods showed a reduction of more than $70 \%$ (Fig. 3).

Abnormalities of sperm tail/intermediate portion of the sperm (Table 1) were influenced by the procedures. MACDGC was able to reduce the proportion of sperm with abaxial/retroaxial implantation. The amount of

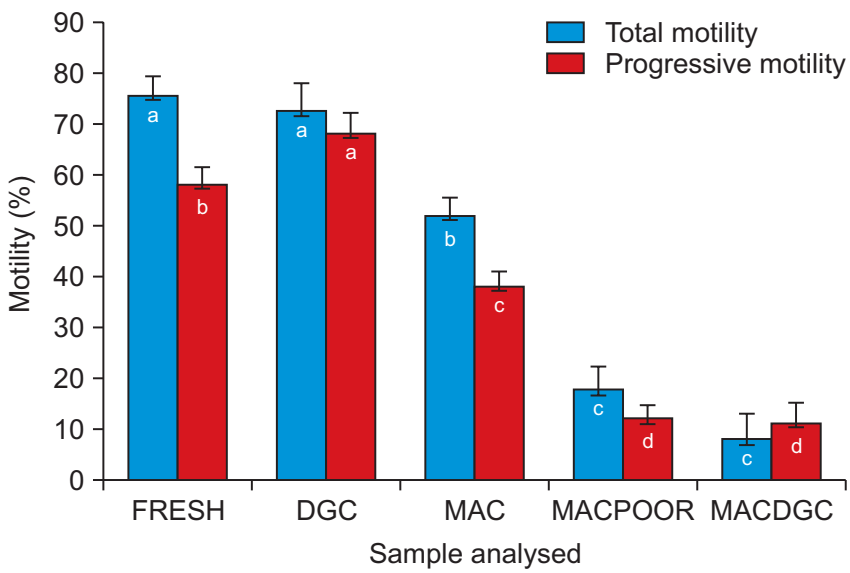

Fig. 2. Total and progressive motility observed in sperm from FRESH, DGC, MAC, MACPOOR, and MACDGC semen samples in Nelore bulls (different letters indicate significant differences, $p<0.5$ ). sperm with normal isolated heads were reduced after all procedures compared to FRESH semen. DGC, the MAC procedure, and the combination of the two (MACDGC) were effective in reducing sperm with strongly folded and curled tails (Table 1). Regarding abnormalities of the sperm head (Table 1), MACS reduced such deformities efficiently. Acrosome defects were retained in the magnetic column (MACPOOR), reducing its proportion in filtered semen (MAC). Also, sperm with abnormal contour were retained in the column (Table 1), and the number of pyriform sperm was reduced to zero after filtering in the column.

The number of live cells (supravital test) was similar in all the samples, with the exception of MACPOOR (Fig. 4). Membrane integrity did not differentiate between FRESH and DGC samples (Fig. 4), but with the other samples, MAC had a $22 \%$ increase over MACPOOR, whereas MACDGC revealed low membrane integrity (32.3\%). The mitochondrial potential was similar in the samples, and although MACPOOR showed a $20 \%$ reduction, it showed no significant difference from the other samples (Fig. 4).

\section{DISCUSSION}

The tested treatments influenced the total and progressive motilities, observing a decrease in motility with increased semen manipulation. DGC increased progressive sperm motility by about $15 \%$ compared to FRESH semen. MAC's motility was over $30 \%$ higher than MACPOOR,

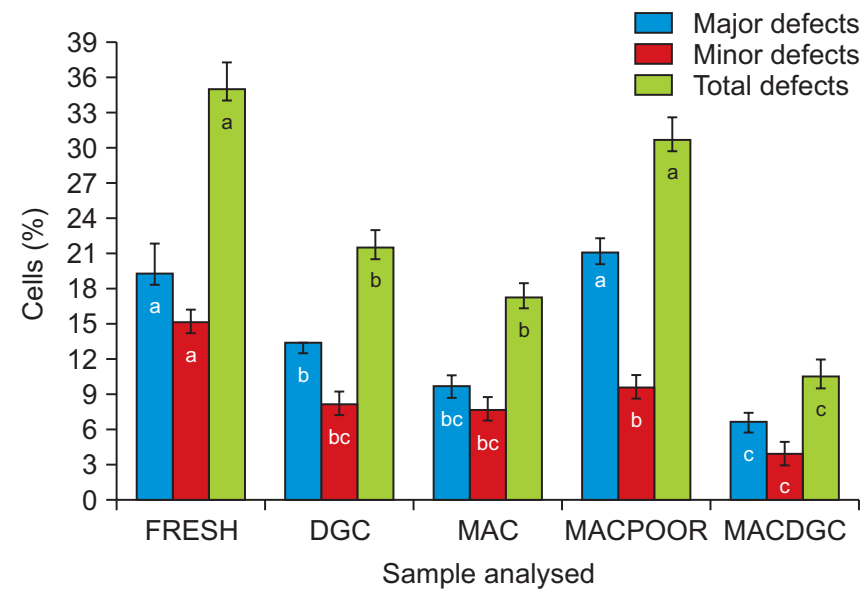

Fig. 3. Major, minor, and total morphological defects seen in sperm from FRESH, DGC, MAC, MACPOOR, and MACDGC semen samples in Nelore bulls (different letters indicate significant differences, $p<$ $0.5)$. 
Table 1. Individual sperm abnormalities (\%) observed in samples of fresh semen, density gradient centrifugation/percoll (DGC), non-apoptotic fraction (MAC), apoptotic fraction (MACPOOR), and MAC followed by DGC/percoll (MACDGC) in Nelore bulls

\begin{tabular}{|c|c|c|c|c|c|}
\hline & FRESH & DGC & MAC & MACPOOR & MACDGC \\
\hline \multicolumn{6}{|l|}{ Midpiece/tail defects } \\
\hline Abaxial/retroaxial & $0.5 \pm 0.2^{a}$ & $0.0 \pm 0.1^{a, b}$ & $0.2 \pm 0.1^{\mathrm{a}, \mathrm{b}}$ & $0.3 \pm 0.1^{\mathrm{a}, \mathrm{b}}$ & $0.1 \pm 0.1^{b}$ \\
\hline Free normal heads & $5.9 \pm 1.2^{\mathrm{a}}$ & $2.8 \pm 0.5^{b}$ & $0.9 \pm 0.2^{b}$ & $2.3 \pm 0.6^{b}$ & $1.0 \pm 0.3^{b}$ \\
\hline Folded tail & $5.9 \pm 1.5$ & $3.0 \pm 0.6$ & $4.4 \pm 0.8$ & $4.7 \pm 0.9$ & $1.7 \pm 0.4$ \\
\hline Curled tail & $1.1 \pm 0.3^{a, b}$ & $0.2 \pm 0.1^{b}$ & $1.5 \pm 0.4^{\mathrm{a}}$ & $0.4 \pm 0.2^{b}$ & $0.6 \pm 0.2^{\mathrm{a}, \mathrm{t}}$ \\
\hline Strongly folded and curled tail & $4.4 \pm 0.9^{\mathrm{a}}$ & $0.8 \pm 0.2^{b}$ & $1.4 \pm 0.4^{b}$ & $4.1 \pm 0.9^{a}$ & $0.9 \pm 0.4^{b}$ \\
\hline Defects of midpiece & $0.2 \pm 0.1$ & $0.1 \pm 0.1$ & $0.2 \pm 0.1$ & $0.1 \pm 0.1$ & 0.0 \\
\hline Distal cytoplasmic droplet & $0.8 \pm 0.3$ & $1.5 \pm 0.7$ & $0.7 \pm 0.3$ & $1.3 \pm 0.7$ & $0.2 \pm 0.1$ \\
\hline Proximal cytoplasmic droplet & $6.9 \pm 1.8$ & $5.3 \pm 1.2$ & $4.4 \pm 1.0$ & $4.4 \pm 1.0$ & $3.0 \pm 1.0$ \\
\hline \multicolumn{6}{|l|}{ Head defects } \\
\hline Acrosome & $3.2 \pm 0.8^{a, b}$ & $2.4 \pm 0.5^{a, b}$ & $0.8 \pm 0.2^{b}$ & $4.3 \pm 0.8^{\mathrm{a}}$ & $0.7 \pm 0.3^{b}$ \\
\hline Abnormal contour & $2.4 \pm 0.6^{b}$ & $2.3 \pm 0.3^{b}$ & $1.3 \pm 0.3^{b}$ & $5.4 \pm 0.8^{\mathrm{a}}$ & $1.5 \pm 0.4^{b}$ \\
\hline Narrow & $0.9 \pm 0.4$ & $0.6 \pm 0.3$ & $0.2 \pm 0.1$ & $0.7 \pm 0.2$ & $0.1 \pm 0.1$ \\
\hline Narrow at base & $0.8 \pm 0.3^{a}$ & $0.5 \pm 0.2^{a, b}$ & $0.0^{b}$ & $0.3 \pm 0.2^{a, b}$ & $0.0^{b}$ \\
\hline Pyriform & $0.1 \pm 0.1$ & $0.2 \pm 0.1$ & 0.0 & $0.2 \pm 0.1$ & 0.0 \\
\hline Pouch formation & $2.6 \pm 0.1$ & $1.3 \pm 0.7$ & $1.3 \pm 0.3$ & $1.9 \pm 0.6$ & $0.7 \pm 0.3$ \\
\hline
\end{tabular}

*Different letters on the lines indicate significant difference $(p<0.05)$ by Tukey test.

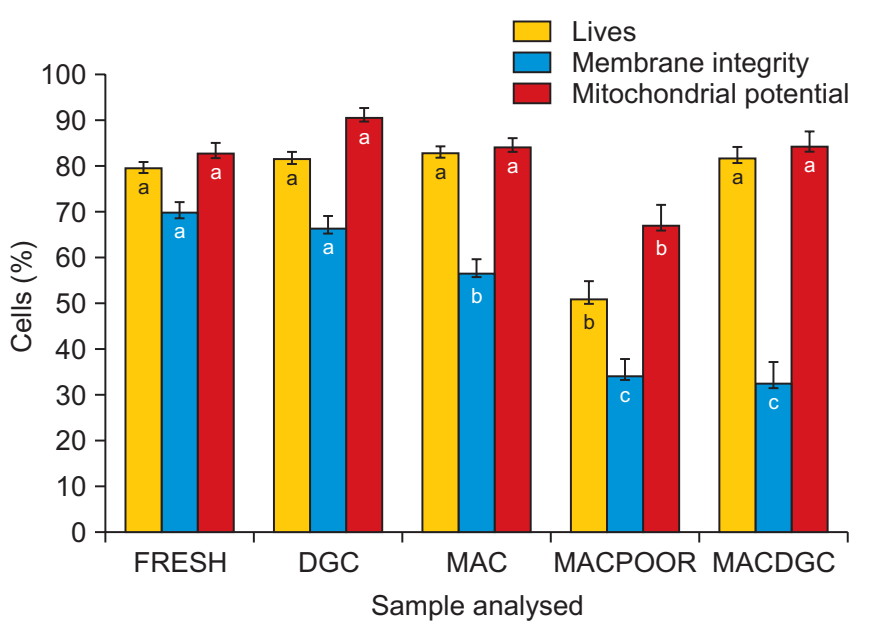

Fig. 4. Total live cells, membrane integrity, and mitochondrial potential of sperm cells in semen samples FRESH, DGC, MAC, MACPOOR, and MACDGC in Nelore bulls (different letters indicate significant differences, $p<0.5$.

and both MACPOOR and MACDGC had the lowest motility values (Fig. 2). Although the DGC technique did not increase total motility, progressive sperm motility was increased by about $15 \%$ compared to FRESH semen. This validates the experimental model, since the percoll column was used to select mobile sperm (Berteli et al., 2017; Missio et al., 2018).

The good portion of the MACS filtrate (MAC) showed lower motility than both FRESH semen and that processed by DGC/percoll, possibly due to increased manipulation of the semen and the need for biochemical adjustments in the filtering medium (Aziz et al., 2007; Berteli et al., 2017). Said and Lang (2011) stated that all advanced methods of sperm selection involve the prolonged exposure of spermatozoa to non-physiological conditions can induce iatrogenic damage, and Rawe et al. (2009) observed that motility decreased by approximately $20 \%$ with the passage through the column since this parameter is mainly influenced by the lower number of fast progressive spermatozoa to the detriment of the higher number of slow progressive ones.

However, MACPOOR showed a 30\% reduction in motility compared to MAC. This shows the column ability to retain apoptotic immobile sperm (Said et al., 2006; de Vantéry Arrighi et al., 2009). MACDGC, on the other hand, had motility as low as MACPOOR, probably due to the number of procedures to which the cell was subjected. Also, both long times of sperm exposure to the filtration means and percoll and long periods between analyses subjected the cells to mechanical and magnetic forces within the column, which can lead to defects in the tail. This can result in a decrease in motility but a high amount of living cells (Aziz et al., 2007; Rawe et al., 2009; Berteli et al., 2017).

When comparing DGC and MACS techniques, we found that both were effective in reducing total sperm abnormalities, with $40 \%$ and $50 \%$ drops, respectively. However, 
the combination of the two methods showed greater efficiency (reduction of more than 70\%), in producing samples with high cell quality, containing only $10.5 \%$ with abnormalities (Fig. 3), as also observed by Faezah et al. (2014) and Odhiambo et al. (2014). Like total defects, major and minor defects also differed between samples. MACPOOR has always presented a high number of abnormalities, mainly major defects. In human semen and in this research, several others have also demonstrated the efficiency of MACS in reducing abnormalities and increasing fertilization rates (Said et al., 2008; Gil et al., 2013; Curti et al., 2014; Bucar et al., 2015; Berteli et al., 2017). These results, verified with DGC and MACS, express their action in the selective removal of tail and head defects. The MACS efficiency is validated by the fact that, according to de Vantéry Arrighi et al. (2009), FTS is present in $61.4 \%$ of the sperm membranes in all regions (head, intermediate part, and tail) with greater expression in the head.

Abnormalities of the sperm tail (Table 1) decreased significantly after DGC compared to FRESH sperm, including folded (5.9 to 3.0), curled (1.1 to 0.2 ), and strongly folded and curled (4.4 to 0.8 ) tails. DGC also contributed to the reduction of other sperm cell defects, though in a more subtle way. Additionally, MACS efficiently reduced sperm head abnormalities (Table 1), with significant decreases in individual defects for MAC compared to FRESH semen: acrosome (3.2 to 0.8 ), abnormal contour (2.4 to 1.3 ), narrow (0.9 to 0.2$)$, narrow at the base (0.8 to 0.0$)$, and pyriform (0.1 to 0.0$)$. MAC also reduced tail defects, being very effective in mitigating strongly folded and curled tails (4.4 to 1.4). Head defects, such as acrosome lesions and abnormal and narrow contour at the base, also showed significant differences between samples. Other spermatic defects, such as normal isolated heads, had reductions of $52 \%$ with DGC/percoll and $85 \%$ in MAC. Pouch formation had a $50 \%$ reduction in both techniques, and midpiece defects reduced by $50 \%$ with DGC/percoll but had no variation with MAC; the two techniques did not show good efficiency for proximal and distal cytoplasmic droplet (Table 1). A similar pattern of sperm morphology after DGC and MACS was observed by Aziz et al. (2007) and Dirican et al. (2008) in human semen. Reductions in individual abnormalities show that each technique is selective for certain sperm defects, but both DGC and MACS, separately or together, contributed to improving cell sample quality.

The number of live cells (supravital test) was similar in the samples, with the exception of MACPOOR, which dropped by $50 \%$ (Fig. 4). MAC showed a slight increase of $4 \%$ in the number of live cells, in relation to FRESH semen, but without significant differences from the other samples. Grunewald et al. (2006) and Faezah et al. (2014) also observed similar results. MACS works by separating cell subpopulations with intact membranes, and like DGC/percoll, it yields a greater number of living cells, thus proving efficient in removing immobile cells from semen samples and achieving low numbers of dead cells in the medium.

Membrane integrity did not differentiate between FRESH and percoll, but with the other samples, MAC exhibited a significant difference compared to MACPOOR (56.6\% and $34.0 \%$, respectively). However, MACDGC revealed low membrane integrity (32.3\%), similar to MACPOOR. This may be due, in part, to the high degree of cell handling during the analyses, which may have caused membrane damage (Fig. 4). These results highlight the efficiency of MACS in removing cells with membrane damage, that are possibly already undergoing apoptosis, and leading to a reduction in the oxidative stress of the sample (Paasch et al., 2003; Grunewald et al., 2006; Aziz et al., 2007; Rawe et al., 2009; Faezah et al., 2014; Manuel et al., 2017).

The mitochondrial potential was similar in all samples, with the exception of MACPOOR, where there was a drop of almost 20\% (Fig. 4). This behavior indicated that most sperm with mitochondrial lesions must be dead or in the process of apoptosis. The DGC/percoll sample exhibited an $8 \%$ increase in mitochondrial potential in relation to the other samples, but with no significant difference from the other samples, indicating that this technique also removes "dead" cells from the medium. Evaluation of the mitochondrial membrane potential serves as a parameter to infer the fertility of the cells because when it is high, we have a good sperm quality, and fertilization capacity of the sperm is linked to motility and is dependent on the mitochondrial function (Kasai et al., 2002; Zorn et al., 2012).

\section{CONCLUSION}

The combination of the two sperm processing methods (DGC and MACS) was very effective in the production of 
high-quality sperm samples, and the subpopulation of non-apoptotic sperm (MAC) revealed a morphologically superior quality. These findings suggest that this nanotechnological method, using nanoparticles, is efficient in the production of high-quality semen samples for use in assisted reproduction procedures in cattle.

\section{CONFLICTS OF INTEREST}

No potential conflict of interest relevant to this article was reported.

\section{ACKNOWLEDGEMENTS}

Dr. Paula A. Navarro, Human Reproduction Division, Department of Gynecology and Obstetrics, Ribeirão Preto School for the temporary assignment of MiniMACS equipment. Alta Genetics, Uberaba, MG for the facilities and animals used in the research. This research did not receive any specific scholarship from public, commercial or non-profit sectors. This study was financed in part (english review service) by the Coordenação de Aperfeiçoamento de Pessoal de Nível Superior - Brasil (CAPES) - Finance Code 001.

\section{AUTHOR CONTRIBUTIONS}

Teresinha Inês de Assumpção: Conceptualization, Data Curation, Formal analysis, Investigation, Methodology, Project administration, Resources, Visualization, Supervision, Writing, Writing - Review \& Editing.

Neimar Correa Severo: Methodology, Validation, Investigation, Resources.

João Pedro Brandão Zandonaide: Methodology, Validation, Investigation, Resources.

Gustavo Guerino Macedo: Conceptualization, Methodology, Validation, Formal analysis, Investigation, Data Curation, Writing, Writing - Review \& Editing.

\section{AUTHOR'S POSITION AND ORCID NO.}

\author{
TI Assumpção, Researcher and Professor, \\ https://orcid.org/0000-0001-8323-9348 \\ NC Severo, Technical consultant, \\ https://orcid.org/0000-0002-6319-6608
}

JPB Zandonaide, $\mathrm{PhD}$ candidate, https://orcid.org/0000-0002-4030-336X

GG Macedo, Researcher and Professor, https://orcid.org/0000-0003-3535-6050

\section{REFERENCES}

ASBIA. 2021. ASBIA Index 2020. http://www.asbia.org.br. Accessed 3 March 2020.

Aziz N, Said T, Paasch U, Agarwal A. 2007. The relationship between human sperm apoptosis, morphology and the sperm deformity index. Hum. Reprod. 22:1413-1419.

Berteli TS, Da Broi MG, Martins WP, Ferriani RA, Navarro PA. 2017. Magnetic-activated cell sorting before density gradient centrifugation improves recovery of high-quality spermatozoa. Andrology 5:776-782.

Bucar S, Gonçalves A, Rocha E, Barros A, Sousa M, Sá R. 2015. DNA fragmentation in human sperm after magnetic-activated cell sorting. J. Assist. Reprod. Genet. 32:147-154.

Celeghini ECC, De Arruda RP, De Andrade AFC, Nascimento J, Raphael CF. 2007. Practical techniques for bovine sperm simultaneous fluorimetric assessment of plasma, acrosomal and mitochondrial membranes. Reprod. Domest. Anim. 42:479-488.

Colégio Brasileiro de Reprodução Animal (CBRA). 2013. Manual para exame andrológico e avaliação de sêmen animal. 3rd ed, CBRA, Belo Horizonte, pp. 103. Portuguese.

Curti G, Skowronek F, Vernochi R, Rodriguez-Buzzi AL, Rodriguez-Buzzi JC, Casanova G, Sapiro R. 2014. Morphological evaluation of sperm from infertile men selected by magnetic activated cell sorting (MACS). Reprod. Biol. 14:289-292.

de Arruda RP, Celeghini ECC, Garcia AR, dos Santos GDC, Leite TG, Oliveira LZ, Lançoni R, Rodrigues MP. 2015. [Bull sperm morphology: interpretation and impact on fertility]. Rev. Bras. Reprod. Anim. 39:47-60.

de Vantéry Arrighi C, Lucas H, Chardonnens D, de Agostini A. 2009. Removal of spermatozoa with externalized phosphatidylserine from sperm preparation in human assisted medical procreation: effects on viability, motility and mitochondrial membrane potential. Reprod. Biol. Endocrinol. 7:1.

Dirican EK, Ozgün OD, Akarsu S, Akin KO, Ercan O, Uğurlu M, Camsari C, Kanyilmaz O, Kaya A, Unsal A. 2008. Clinical outcome of magnetic activated cell sorting of non-apoptotic spermatozoa before density gradient centrifugation for assisted reproduction. J. Assist. Reprod. Genet. 25:375-381.

Faezah SS, Zuraina FM, Farah JH, Khairul O, Hilwani NI, Iswadi MI, Fang CN, Zawawi I, Abas OM, Fatimah SI. 2014. The effects of magnetic separation on cryopreserved bovine spermatozoa motility, viability and cryo-capacitation status. Zygote 22:378-386.

Gil M, Sar-Shalom V, Melendez Sivira Y, Carreras R, Checa MA. 2013. Sperm selection using magnetic activated cell sorting (MACS) in assisted reproduction: a systematic review and 
meta-analysis. J. Assist. Reprod. Genet. 30:479-485.

Grunewald S, Paasch U, Said TM, Rasch M, Agarwal A, Glander HJ. 2006. Magnetic-activated cell sorting before cryopreservation preserves mitochondrial integrity in human spermatozoa. Cell Tissue Bank. 7:99-104.

Kasai T, Ogawa K, Mizuno K, Nagai S, Uchida Y, Ohta S, Fujie M, Suzuki K, Hirata S, Hoshi K. 2002. Relationship between sperm mitochondrial membrane potential, sperm motility, and fertility potential. Asian J. Androl. 4:97-103.

Kurz A, Viertel D, Herrmann A, Müller K. 2005. Localization of phosphatidylserine in boar sperm cell membranes during capacitation and acrosome reaction. Reproduction 130:615626.

Machado GM, Carvalho JO, Filho ES, Caixeta ES, Franco MM, Rumpf R, Dode MA. 2009. Effect of Percoll volume, duration and force of centrifugation, on in vitro production and sex ratio of bovine embryos. Theriogenology 71:1289-1297.

Manuel TJ, José MM, María CA, Carlos Z, Estela MP. 2017. Use of annexin $\mathrm{V}$ based sperm selection in assisted reproduction. Andrology (Los Angel.) 6:1000182.

Missio D, Folchini NP, Leivas FG, Pavin CIIUM, Pinto HF, Cibin FWS, Brum DDS. 2018. Reduction in Percoll volume increases recovery rate of sex-sorted semen of bulls without affecting sperm quality and early embryonic development. Anim. Reprod. Sci. 192:146-153.

Nöthling JO and Irons PC. 2008. A simple multidimensional system for the recording and interpretation of sperm morphology in bulls. Theriogenology 69:603-611.

Odhiambo JF, DeJarnette JM, Geary TW, Kennedy CE, Suarez SS, Sutovsky M, Sutovsky P. 2014. Increased conception rates in beef cattle inseminated with nanopurified bull semen. Biol. Reprod. 91:97.

Paasch U, Grunewald S, Fitzl G, Glander HJ. 2003. Deterioration of plasma membrane is associated with activated caspases in human spermatozoa. J. Androl. 24:246-252.

Rawe V, Álvarez G, Uriondo H, Papier S, Miasnik S, Nodar F. 2009. Separación magnética por columnas de anexinas V: "filtrado molecular" para la selección de espermatozoides no apoptóticos. Reproduccion 24:104-114. Spanish.

Sá Filho OG, Meneghetti M, Peres RF, Lamb GC, Vasconcelos JL. 2009. Fixed-time artificial insemination with estradiol and progesterone for Bos indicus cows II: strategies and factors affecting fertility. Theriogenology 72:210-218.

Said T, Agarwal A, Grunewald S, Rasch M, Baumann T, Kriegel C, Li L, Glander HJ, Thomas AJ Jr, Paasch U. 2006. Selection of nonapoptotic spermatozoa as a new tool for enhancing assisted reproduction outcomes: an in vitro model. Biol. Reprod. 74:530-537.

Said TM, Agarwal A, Zborowski M, Grunewald S, Glander HJ, Paasch U. 2008. Utility of magnetic cell separation as a molecular sperm preparation technique. J. Androl. 29:134-142.

Said TM and Land JA. 2011. Effects of advanced selection methods on sperm quality and ART outcome: a systematic review. Hum. Reprod. Update 17:719-733.

Tavalaee M, Deemeh MR, Arbabian M, Nasr-Esfahani MH. 2012. Density gradient centrifugation before or after magnetic-activated cell sorting: which technique is more useful for clinical sperm selection? J. Assist. Reprod. Genet. 29:3138.

Valverde A and Madrigal-Valverde M. 2018. Computer-assisted semen analysis systems in animal reproduction. Agron. Mesoam. 29:469-484.

Zorn B, Golob B, Ihan A, Kopitar A, Kolbezen M. 2012. Apoptotic sperm biomarkers and their correlation with conventional sperm parameters and male fertility potential. J. Assist. Reprod. Genet. 29:357-364. 